\title{
Disabling injuries of the cervical spine in Argentine rugby over the last 20 years
}

Centro de Educación Médica e

Investigaciones,

Clínicas Norberto

Quirno, Buenos Aires,

Argentina

F P Secin

Medical Committee of the Argentine Rugby Union (UAR)

E J T Poggi

F Luzuriaga

Surgical Services, Norwalk Hospital, Norwalk, CT, USA H A Laffaye

Correspondence to: F P Secin, Montes de Oca 630 6A (1270), Buenos Aires, Argentina.

Accepted for publication 21 October 1998

Fernando P Secin, Eduardo J T Poggi, Felix Luzuriaga, Horacio A Laffaye

\begin{abstract}
Objective-To investigate the incidence and risk factors of disabling injuries to the cervical spine in rugby in Argentina.

Methods-A retrospective review of all cases reported to the Medical Committee of the Argentine Rugby Union (UAR) and Rugby Amistad Foundation was carried out including a follow up by phone. Cumulative binomial distribution, $\chi 2$ test, Fisher test, and comparison of proportions were used to analyse relative incidence and risk of injury by position and by phase of play (Epi Info 6, Version 6.04a). Results-Eighteen cases of disabling injury to the cervical spine were recorded from 1977 to 1997 ( 0.9 cases per year). The forwards (14 cases) were more prone to disabling injury of the cervical spine than the backs (four cases) $(p=0.03)$. Hookers (9/18) were at highest risk of injury $(p<0.01)$. The most frequent cervical injuries occurred at the 4 th, 5th, and 6 th vertebrae. Seventeen of the injuries occurred during match play. Set scrums were responsible for most of the injuries (11/18), but this was not statistically significant $(p=0.44)$. The mean age of the injured players was 22 . Tetraplegia was initially found in all cases. Physical rehabilitation has been limited to the proximal muscles of the upper limbs, except for two cases of complete recovery. One death, on the seventh day after injury, was reported. Conclusions-The forwards suffered a higher number of injuries than the backs and this difference was statistically significant. The chance of injury for hookers was statistically higher than for the rest of the players and it was particularly linked to scrummaging. However, the number of injuries incurred in scrums was not statistically different from the number incurred in other phases of play.

(Brf Sports Med 1999;33:33-36)
\end{abstract}

Keywords: cervical; spine; rugby; injury; quadriplegia

Injuries are a complication relevant to all sports, especially the so-called contact sports. In 1981, Sparks ${ }^{1}$ reported that the rate of injury was higher in rugby than in any other sport. Disabling cervical spine injuries occur particularly in rugby. This problem has been recognised since the mid-1970s. ${ }^{2-11}$ Unlike the rest of the spine, the cervical cord is particularly vulnerable to injury because it has ${ }^{2}{ }^{12-17}$.

(1) greater mobility;

(2) smaller vertebral bodies;

(3) oblique articular facets;
(4) weaker muscle protection;

(5) relative mobility of the unsupported skull on the cervical spine.

The likelihood of injury is enhanced by the fact that, in rugby, the player leads with the head.

Cervical injury is the result of either extreme flexion with or without rotation of the neck or hyperextension of cervical vertebrae. Hyperflexion lesions are most common and occur when a force is exerted through the vertex of the head and transmitted through the skull to the cervical vertebrae. The vertebrae crush and the vertebral body and disc extrude posteriorly into the cervical cord. Dislocation may occur without fracture of the vertebrae. Forced flexion of the neck is observed most frequently during collapse of the scrum while the scrum or the opposition continue to push. Other potential injury conditions include wheeling of a scrum and when players turn their necks to look at an incoming ball. Cord injuries are predominantly at the level of C4, C5, and C6. The neck of a tight front row is estimated to brace $1-1.5$ tons in each scrum.

During extreme extension of the neck, the spinal canal is narrowed and the cord may be seriously damaged. If the force of the impact is great enough, fracture of the posterior bony elements occurs as they impinge on one another. Brain damage may arise if the vertebral artery is compressed between the occipital condyles of the skull and the lamina of the first cervical vertebra. ${ }^{16}$ This kind of damage is typically seen when the front rows "charge in" during the engagement of the scrum and the head of a player is not correctly aligned; the head is lifted out of the scrum ("pop out"). Incorrect tackling technique can also result in whiplash hyperextension neck injuries.

This study looks at the number of rugby players who have suffered this lesion in Argentina during the last 20 years and the circumstances under which the injury occurred. Age, field position, phase of play, and rule amendments are all considered.

\section{Methods}

All rugby players of any category were included in the study if they had suffered a clinically permanent or transient disabling cervical spine injury. Head trauma and disabling injuries not affecting the cervical column were excluded. The design was descriptive. Information on all cases involving this type of injury was obtained from the Argentine Rugby Union (UAR) and the Rugby Amistad Foundation. The latter foundation involves rugby players who have suffered a disabling injury of any type in rugby and focuses on rehabilitation both physical and 
Table 1 List of cases of disabling injury to the cervical spine in Argentine rugby

\begin{tabular}{|c|c|c|c|c|c|c|c|c|c|}
\hline No & $\begin{array}{l}\text { Age } \\
\text { (years) }\end{array}$ & $\begin{array}{l}\text { Date of } \\
\text { injury }\end{array}$ & $\begin{array}{l}\text { Level of } \\
\text { injury }\end{array}$ & Tracheostomy & Surgery & Delay & Position & Mechanism & Rehabilitation \\
\hline 1 & 16 & $25 / 05 / 77$ & 5 & Yes & Yes & 7 days & Hooker & Collapsed scrum & Shoulders and biceps \\
\hline 2 & 25 & $8 / 10 / 78$ & 6,7 & No & Yes & 6 hours & Prop & Scrum engagement & Upper limbs \\
\hline 3 & 17 & $11 / 03 / 86$ & 6,7 & No & Yes & 7 days & Flanker & Collapsed scrum & Upper limbs \\
\hline 4 & 19 & $7 / 07 / 86$ & 6 & - & - & & Hooker & Collapsed scrum & Shoulders and biceps \\
\hline 5 & 15 & $26 / 09 / 87$ & 5,6 & No & Yes & 7 hours & Hooker & Collapsed maul & Upper limbs \\
\hline 6 & 15 & $7 / 07 / 88$ & & - & - & & Hooker & Scrum engagement & Death 7 th day \\
\hline 7 & 17 & $29 / 07 / 89$ & 4,5 & No & Yes & & Hooker & Collapsed scrum & Biceps \\
\hline 8 & 21 & $7 / 10 / 90$ & 5,6 & No & Yes & 6 hours & Fly half & Tackler & Upper limbs and part of lower limbs \\
\hline 9 & 18 & $17 / 07 / 93$ & 2,3 & Yes & Yes & 4 days & Lock & Scrum engagement & Left body \\
\hline 10 & 23 & $29 / 08 / 93$ & 6,7 & No & Yes & 7 days & No 8 & Collapsed maul & Upper limbs \\
\hline 11 & 19 & $13 / 03 / 94$ & 4,5 & No & Yes & & Centre & Tackler & Upper limbs \\
\hline 12 & 27 & $6 / 07 / 94$ & 2,3 & No & No & & Centre & Tackler & Complete \\
\hline 13 & 17 & $3 / 09 / 94$ & 5,6 & No & Yes & 2 hours & Hooker & Collapsed scrum & Upper limbs \\
\hline 14 & 22 & $20 / 06 / 95$ & 4,5 & No & Yes & 10 days & Wing & Tackled & Complete \\
\hline 15 & 24 & $12 / 08 / 95$ & 5,6 & No & Yes & 8 hours & Hooker & Scrum engagement & Upper limbs \\
\hline 16 & 17 & $23 / 06 / 96$ & 5,6 & No & Yes & 1 day & Hooker & Scrum engagement & Almost complete \\
\hline 17 & 26 & $28 / 07 / 96$ & 2,3 & Yes & Yes & 4 days & Lock & Tackled & Right hemibody \\
\hline 18 & 20 & $19 / 10 / 97$ & 5,6 & No & Yes & 7 days & Hooker & Scrum engagement & Left shoulder \\
\hline
\end{tabular}

Delay indicates the delay between injury and surgery.

Blank spaces correspond to unavailable data.

psychological. A follow up on the phone was carried out. Cumulative binomial distribution, $\chi^{2}$ and Fisher tests, and comparison of proportions were used to analyse risk of injury by position and by phase of play (Epi Info 6, Version 6.04a). Table 1 gives the files describing each case and affiliated data. As far as we know, there were no cases or deaths that were not reported to the medical committee.

\section{Results}

Eighteen cases of disabling injury to the cervical spine have been recorded since 1977 . The ages of the injured players ranged from 15 to 27 , the mean being 22 (table 1). Fractures or dislocations between the 4 th and 6 th cervical vertebrae were most common. All cases were treated surgically. Three of the patients needed tracheostomy. The delay before surgery after the accident ranged from two hours to 30 days.

Statistical analysis showed that the forwards (14 cases) had a higher risk of injury than the backs (four cases). The proportion of forwards who received an injury to the cervical spine was $14 / 18$ - that is, 0.778 . The proportion expected from the number of players actually playing in a game is $8 / 15$-that is, 0.533 . The cumulative binomial distribution was 0.97 , which gives a $\mathrm{p}$ value of 0.03 for a one tailed test.

The playing position in which injury most frequently occurred was hooker (nine), then inside centre (two), third row (two), second row (two), prop (one), wing (one), and fly half (one). Hookers had a statistically higher risk of injury than the rest of the players $\left(\chi^{2}\right.$ test with Yates correction: $p<0.01)$ As the $\chi^{2}$ test was considered not valid because the expected value for Hookers was less than 5, the Fisher test proved that hookers experienced a statistically significantly increased chance of a disabling cervical spinal injury $(\mathrm{p}<0.0004)$.

Scrummaging was responsible for $11 / 18$ cases of injury; six occurred during scrum engagement and five were the result of scrum collapse. The second most frequent cause of injury was the tackle (five). In three cases, the tackler was affected and in two the tackled player. The next most frequent cause of injury was collapse of the maul (two). Comparison of proportions between disabling cervical spine injury caused by scrums and other formations did not show any statistically significant difference $(p=0.44)$.

Almost all injuries (17/18) occurred during match play, as opposed to training sessions. Quadriplegia was the main clinical manifestation in all cases. Except for two cases of complete neurological recovery, all players experienced different degrees of neurological sequelae (table 1). Only one death, from pulmonary infection in the intensive care unit on the seventh day after injury, was registered.

\section{Discussion}

The most distinctive characteristic of rugby in the last 25 years has been the high annual incidence of spinal cord injuries reported in many rugby playing countries such as New Zealand, ${ }^{15}{ }^{17}$ England, ${ }^{30}$ Australia, ${ }^{18}$ Ireland, ${ }^{19}$ and France (unpublished data). Even countries that have started to participate in international rugby fairly recently, such as Canada and the United States, have reported the same increased incidence. $^{2}$

Silver ${ }^{10}$ observed that the average number of cervical spinal cord injuries in England each year was 2.2 between 1956 and 1982 . This rose to 3.6 per annum between 1982 and 1987 . The annual mean number of disabling injuries of the cervical spine in Argentina from 1977 to 1997 was 0.9 - that is, less than one case a year. However, 14/18 cases occurred during the last 10 years, with an annual average of 1.4 cases since 1987. These figures are not comparable from a statistical viewpoint. Whereas the Rugby Football Union includes about 400000 players, the Argentine Rugby Union has only 48000 . Furthermore, 25000 players are aged under 19 in Argentina, and juveniles play an average of 15 games per year compared with 20 matches played by adults in Argentina. In other countries, such as those of the British Isles, an adult player is estimated to take part in 30 matches per annum.

As could be expected from the nature of the game, the number of injuries to forwards $(77 \%)$ was significantly higher than the number of injuries to backs $(23 \%)(p=0.03)$. There are 
Table 2 Main rule modifications concerning the scrum

\begin{tabular}{cl}
\hline Year & Rule \\
\hline 1978 & $\begin{array}{l}\text { The shoulders must be above the level of the hip. It is not allowed to hook the ball } \\
\text { with the head. }\end{array}$ \\
1980 & $\begin{array}{l}\text { Right prop must grab the opposite prop above the shoulder. This does not apply for } \\
\text { the left prop. }\end{array}$ \\
1982 & $\begin{array}{l}\text { Intentional collapse of the scrum is penalised. } \\
1983\end{array}$ \\
1985 & $\begin{array}{l}\text { The forwards, particularly the right prop, must push in a straight line during the shove. } \\
\text { The scrum cannot drive more than } 1 \mathrm{~m} \text {. Wheeling is limited to } 45^{\circ} \text { in young divisions }\end{array}$ \\
1988 & $\begin{array}{l}\text { Sequential alignment is enforced (front row first, then second row and finally third } \\
\text { row). This technique increased the number of collapses and the rule was changed. }\end{array}$ \\
1989 & $\begin{array}{l}\text { The crouch-pause-engage sequence is introduced. Scrum half should be ready to put } \\
\text { the ball in before the engagement to reduce the time of the formation. }\end{array}$ \\
1991 & $\begin{array}{l}\text { Should a team be unable to provide competent players for the front row, the referee } \\
\text { will not permit the game to proceed. }\end{array}$ \\
1994 & $\begin{array}{l}\text { Teams should have a complete front row on the bench. If any player of the front row is } \\
\text { sent off, another first rower should replace any other player to cover the position. }\end{array}$
\end{tabular}

comparable data for England ${ }^{310}$ and South Africa. ${ }^{2}$ Silver ${ }^{3}$ reported a $65 \%$ incidence for the forwards and $35 \%$ for the backs in 57 Rugby Union players who sustained cervical spinal injuries between 1952 and 1982. The same author saw the figures change to 77 and $23 \%$ of 18 injuries between 1982 and 1987. Kew et al retrospectively studied 117 catastrophic neck injuries in rugby players between 1963 and 1989 , and reported a $57 \%$ corrected incidence for the forwards and $43 \%$ for the backs.

Hooker was the most affected position on the field. This finding agrees with reports from South Africa, New Zealand, and the United States, but, in Wales, the injury rate for props was twice as high as that for hookers. It has been reported that mismatches of skill and strength between opponents increase lesion possibilities. $^{23910141520}$

The most obvious risk factor for cervical spinal cord injuries was match play: 17 injuries took place during match play. Similar percentages were reported for rugby in South Africa and Australia. $^{2321}$ This finding is particularly meaningful as considerably more time is spent in practice than in matches. Only one player (no 12 in table 1) was injured during a training session and developed spinal shock for 60 minutes.

It was originally believed that schoolboy rugby players were at greatest risk of spinal cord injury. The literature is full of controversy on this subject. ${ }^{216202223}$ In this study, 8/18 cases involved players aged between 15 and 17 . Furthermore, six of the nine injured hookers were between 15 and 17 .

There were no injuries to players younger than 14 . This finding may be explained by the fact that under-14 teams play the so-called "simulated scrum". In Argentina, static formations (lineouts and scrums) become more relevant in higher competition categories where the level of performance rises and the competitive nature of the game reaches higher levels.

It is arguable whether injuries to young players can be explained by the current more aggressive approach to the game, with a "win at all costs" attitude. Therefore skill does not seem to prevent injuries. This is further backed up by the fact that these injuries take place almost exclusively during match play.

The phase of play in which the lesion occurred varied according to player position. Backs suffered most of their injuries during tackles whereas props and hookers were more prone to injury while scrummaging. Ruck and maul injuries appeared to be more common in forwards. The scrum was responsible for more than half of cervical injuries in Argentina $(11 / 18)$; the majority occurred during the engagement (6/11), and downward collapse of the formation accounted for $5 / 11$ cases. No cervical cord injuries resulted from pop up of the scrum.

The front row is usually more prone to collapse of the scrum when ${ }^{14}$ :

(1) the two front rows charge in during the engagement;

(2) the two front rows stand too close to each other;

(3) the second row and third row forwards apply the push before the front row is properly formed;

(4) the second shove is not made straight forward;

(5) the crotch binding technique is exercised (second row binds on to the prop's jersey by reaching between his legs) adding to the downward force at engagement;

(6) the formation of the scrum takes a long time;

(7) there is incorrect body alignment - that is, shoulders are below the level of the hip;

(8) there is downward push in the second shove;

(9) the playing surface is wet or soft.

Tight forwards often have premature cervical osteoarthrosis and are thus at greater risk of hyperextension injuries to the cervical spinal cord. ${ }^{24} 25$

The second most common mechanism of injury in the study was the tackle $(5 / 18)$. It has been noted that the percentage of disabling cervical injuries sustained through tackling has increased recently in South Africa ${ }^{14}{ }^{15} 20$ and New Zealand. ${ }^{2}$ Injuries to the tackler are often the result of incorrect tackling technique, particularly in the dive tackle. Injuries to the tackled player are caused by a high tackle around the neck, a late or early tackle, and a stiff arm tackle. ${ }^{20}$

We recorded five cases of injury that were due to the tackle, four of which occurred when the ensuing pile up collapsed on the neck of either the tackling player or the player being tackled. The other case of injury caused by the tackle occurred when the neck of the tackled player hyperextended after the chin had hit the ground.

Examination of the time of the season at which the injuries occurred disclosed that $6 / 18$ occurred in July (before the mid-season interval). In contrast, other reports state that most cervical injuries occur at the start of the season or after the mid-season break. ${ }^{216}$ It is hard to find a clear explanation for our finding, which was not statistically significant.

There have been nine amendments to the rules of rugby with respect to the scrum since 1978 (table 2). Half of the injuries in this study took place between 1992 and 1997. Unlike in New Zealand, Australia, and England, these changes to the laws of rugby do not appear to have reduced the number of critical injuries of the cervical spine in Argentina. 
The treatment of cervical fracturedislocation is well established on arrival of the patient at hospital: skull traction, reduction of dislocation, and, sometimes, spinal fusion. However, there is major concern about the immediate management of the critically injured rugby player at the ground. ${ }^{16} \mathrm{~A}$ severely injured player may be extremely breathless for two reasons: firstly, he/she has just been exerting great physical effort; secondly, if the intercostal muscles are paralysed, he/she immediately becomes completely dependent on the diaphragm to meet respiratory requirements. Shortness of breath may be mistaken for airway obstruction by inexperienced personnel, and the player may be placed in the "recovery position" with neck flexed and rotated, which could lead to a total transection of a previously partly damaged cervical cord.

Once quadriplegia is established the prognosis is very poor, as recovery is usually limited to the proximal muscles of the upper limbs (table 1). In this study, there were only two cases of full recovery. In the first, the patient improved over the hours immediately after the spinal shock, and, in the second, the patient recuperated after about six months of physiotherapy.

Many measures can be taken to decrease the chances of injuring the cervical spine. All players, coaches, referees, parents, doctors, and supporters should be made aware of the dangers related to neck injury, particularly those associated with the scrum and tackle. Individual skills in tackling technique should be reviewed and rule amendments should be constantly updated.

The authors would like to thank Mr Ignacio Rizzi, President of the Rugby Amistad Foundation, for information retrieval and Dr Joaquín Paz for help with statistical analysis.

1 Sparks JP. Half a million hours of rugby football: the injuries. Br $\mathcal{F}$ Sports Med 1981;15:30-2.

2 Kew T, Noakes TD, Kettles AN, et al. S Afr Med f 1991;80: $127-33$
3 Silver JR. Injuries of the spine sustained in rugby. $B M 7$ 1984;288:37-43.

4 Conor O. Retrospective survey of rugby injuries in the Leinster province of Ireland 1987-1989. Br F Sports Med 1992; 26:243-4.

5 Waller AE, Feehan M, Marshall SW, et al. The New Zealand rugby injury and performance project. 1. Design and methodology of a prospective follow up study. $\mathrm{Br} \mathcal{F}$ Sports Med 1994;28:223-8.

6 Gerrard DF, Waller AE, Bird YN. The New Zealand rugby injury and performance project. 2. Previous injury experience of a rugby playing cohort. $\mathrm{Br} \mathcal{F}$ Sports Med 1994;28:229-33.

7 Gilfeather B. Rugby. The Practitioner 1989;233:534-5.

8 Gibbs N. Injuries in professional rugby league. A three year prospective study of the South Sidney professional rugby league football club. Am 7 Sports Med 1993;21:696-700.

9 Davies JE, Gibson T. Injuries in rugby union football. BMF $1978 ; 2: 1759-61$.

10 Silver JR. Injuries of the spine sustained during rugby. $\mathrm{Br} \mathcal{F}$ Sports Med 1992;26:253-8.

11 Nicholl JP, Coleman P, Williams BT. A national study of the epidemiology of excercise-related injury and illness: a report to the Sports Council. Sheffield: Medical Care Research Unit, Department of Public Health and Medicine, University of Sheffield Medical School, 1991.

12 Armour KS, Clatworthy BJ, Bean AR, et al. Spinal injuries in New Zealand Rugby and Rugby League: a twenty year survey. N Z Med f 1997;110:462-5.

13 Reid SE, Reid SE Jr. Advances in sports medicine. Prevention of head and neck injuries in football. Surg Ann 1981;13:251-70

14 Milburn PD. Biomechanics of rugby union scrummaging. Technical and safety issues. Review article. Sports Med 1993;16:168-79.

15 Burry HC, Calcinai CJ. The need to make rugby safer. BMF 1988;296:149-50.

16 McCoy GF, Piggot J, Macafee AL, et al. Injuries of the cervical spine in schoolboy rugby football. F Bone foint Surg [Br] 1984;66:500-3.

17 Silver RJ, Stewart D. The prevention of spinal injuries in rugby football. Paraplegia 1994;32:442-53.

18 Vanderfield G. Spinal injuries in rugby football: vital statistics over the last ten years. Paraplegia 1987;25:410.

19 O'Carrol PF, Sheehan JM, Gregg TM. Cervical spine injuries in rugby football. Ir Med $\mathcal{F} 1981 ; 74: 377-9$.

20 Scher AT. Catastrophic rugby injuries of the spinal cord: changing patterns of injury. Brf Sports Med 1991;25:57-60.

21 Cantu RV, Cantu RC. Guidelines for return to contact sports after transient quadriplegia. Neurosurgical forum. Letters to the editor. F Neurosurg 1994;80:592-4.

22 Clark DR, Roux C, Noakes TD. A prospective study of the incidence and nature of injuries to adult rugby players. $S$ Afr Med 7 1990;77:559-62.

23 Horan FT. Injuries to the cervical spine in schoolboys playing rugby football. $\mathcal{F}$ Bone foint Surg 1984;66:470-1.

24 Scher AT. Premature onset of degenerative disease of the cervical spine in rugby players. $S$ Afr Med F 1990;77:557-8.

25 Scher AT. Cervical vertebral dislocation in a rugby player with congenital vertebral fusion. Br f Sports Med 1990;24: $167-8$

\section{Take home message}

The paper tries to emphasise, and warn at the same time, that disabling injuries to the cervical spine are still an intractable problem in Argentina. The highest incidence is in hookers, and its association with scrums calls for further investigation in order to find a pragmatic solution.

\section{Commentary}

This paper is valuable in pointing out that injuries to the spine are still occurring in rugby and they are occurring in the Argentine.

Theoretically, the easiest problem to tackle is the problem of the scrum, and efforts have been made throughout the world to depower the scrum and make it safer. Despite this, these injuries are still occurring and it is noteworthy that they are predominantly in the front row.

Other studies ${ }^{12}$ have found a larger number of forwards injured than backs because forwards today run about and can injure their necks in a tackle, in the same way as the backs, but, in addition, they have the risk of being injured in the scrum.

It has to be recognised that the Argentine forwards are particularly powerful in the scrummage and use different techniques to achieve their domination over the unfortunate forwards of the opposing team. This may well account for the large number of injuries in the front row.

J R SILVER

Wendover, Bucks

1 Armour KS, Clatworth BJ, Bean AR, et al. Spinal injuries in New Zealand and rugby and rugby league: a twenty year survey. NZ Med 7 1997;110:462-5.

2 Silver JR. Injuries of the spine sustained in rugby. BMF 1984;288:37-43. 